\title{
Long-term Emergency Department Visits and Readmissions After Laparoscopic Roux-en-Y Gastric Bypass: a Systematic Review
}

\author{
N. van Olst ${ }^{1}$ - A. S. van Rijswijk ${ }^{1}$ - S. Mikdad ${ }^{2}$ - L. J. Schoonmade ${ }^{3}$ - A. W. van de Laar ${ }^{1}$ - Y. I. Z. Acherman ${ }^{1}$ - S. C. Bruin ${ }^{1}$ \\ D. L. van der Peet $^{2} \cdot$ L. M. de Brauw ${ }^{1}$
}

Received: 9 July 2020 / Revised: 8 February 2021 / Accepted: 9 February 2021 / Published online: 4 April 2021

(C) The Author(s) 2021

\begin{abstract}
Purpose There is considerable evidence on short-term outcomes after laparoscopic Roux-en-Y gastric bypass (LRYGB), but data on long-term outcome is scarce, especially on postoperative emergency department (ED) visits and readmissions. We aim to systematically review evidence on the incidence, indications, and risk factors of ED visits and readmissions beyond 30 days after LRYGB.

Materials and Methods A systematic search in PubMed, Scopus, Embase.com, Cochrane Library, and PsycINFO was performed. All studies reporting ED visits and readmissions $>30$ days after LRYGB, with $\geq 50$ patients, were included. PRISMA statement was used and the Newcastle-Ottawa Scale for quality assessment.

Results Twenty articles were included. Six studies reported on ED visits $(n=2818)$ and 19 on readmissions $(n=$ 276,543). The rate of patients with an ED visit within 90 days after surgery ranged from 3.9 to $32.6 \%$. ED visits at 1,2 , and 3 years occurred in $25.6 \%, 30.0 \%$, and $31.1 \%$ of patients. Readmissions within 90 days and at 1-year follow-up ranged from 4.1 to $20.5 \%$ and 4.75 to $16.6 \%$, respectively. Readmission was $29 \%$ at 2 years and $23.9 \%$ at 4.2 years of follow-up. The most common reason for ED visits and readmissions was abdominal pain.

Conclusion Emergency department visits and readmissions have been reported in up to almost one in three patients on the longterm after LRYGB. Both are mainly indicated for abdominal pain. The report on indications and risk factors is very concise. A better understanding of ED visits and readmissions after LRYGB is warranted to improve long-term care, in particular for patients with abdominal pains.
\end{abstract}

Keywords Roux-en-Y gastric bypass $\cdot$ Emergency department visits $\cdot$ Readmissions

\section{Key Points}

- Emergency department visits and readmissions have been reported in up to almost one in three patients on the long-term after LRYGB.

- Only nine studies in the current literature had data on emergency department visits and readmissions beyond 90 days after LRYGB.

- Abdominal pain is the main reason for long-term emergency department visits and readmissions after LRYGB.

N. van Olst

nvanolst@ spaarnegasthuis.nl

1 Department of Surgery, Spaarne Gasthuis, Spaarnepoort 1, 2134 TM Hoofddorp, The Netherlands

2 Department of Surgery, Amsterdam UMC, De Boelelaan 1117, 1081 HV Amsterdam, The Netherlands

3 Medical Library, Vrije Universiteit Amsterdam, De Boelelaan 1117, P.O. Box 7057, 1007 MB Amsterdam, The Netherlands

\section{Introduction}

Bariatric surgery has gained ground due to the increasing prevalence of obesity over the past decades [1-3]. Worldwide, the number of bariatric surgeries performed nearly doubled between 2008 and 2016 and approached 700,000 procedures in 2016 [4]. The laparoscopic Roux-en-Y gastric bypass (LRYGB) is still one of the most commonly performed bariatric surgeries in the world $[4,5]$. It induces sustainable weight loss, and has proven to be a viable solution for obesityrelated comorbidities and reduces overall mortality [6-10]. The LRYGB can be considered safe, with acceptable morbidity and mortality rates within 30 days of surgery $[6,9]$.

Two quality measures after LRYGB surgery are emergency department (ED) visits and readmissions. These are considered to be markers of poor coordination of care and provide insight in the complications during post-bariatric care. They 
also reflect the long-term impact that a given intervention may have on public health, and healthcare systems, with direct and indirect financial consequences. There is extensive evidence on the short-term outcomes after LRYGB with 5.1-6.1\% readmissions and $11.3 \% \mathrm{ED}$ visits in the first 30 days after surgery [11-13]. The most frequently met long-term complications are internal herniation, ulcers at the gastrojejunal anastomosis, and cholelithiasis [14-18]. Also complaints of diarrhea, fatigue, anemia, hypoglycemia, and dumping are often present [19]. The magnitude and impact of these long-term complaints are less evident.

With a growing number of bariatric surgeries, improvement of long-term care after LRYGB is necessary. The primary aim of this study is to review the current literature focusing on the number and reasons for ED visits and readmission $>30$ days after LRYGB. Insight in occurrence, diagnostics, and treatment of long-term complaints is essential. Therefore, it is important to score reasons for long-term ED visits and readmissions.

\section{Materials and Methods}

\section{Data Sources}

This systematic review was conducted in accordance with the Preferred Reporting Items for Systematic Reviews and MetaAnalysis (PRISMA) statement [20]. A comprehensive search was performed, in collaboration with a medical librarian (LS), in the bibliographic databases PubMed, Embase.com, PsycINFO (via Ebsco), the Cochrane Library, and Scopus from inception to October 17, 2019. Search terms included controlled terms (MeSH in PubMed, Emtree in Embase, and thesaurus terms in PsycINFO) as well as free-text terms. The following terms were used, including synonyms and closely related words, as index terms or free-text words: "bariatric surgery" and "readmission" or "emergency department visit. "The search was performed without date or language restrictions. Furthermore, the references of the included articles were manually screened for cross-references. The full search strategies for all databases can be found in Supplement 1 .

\section{Main Outcomes and Measures}

The primary outcome measure of this study is the number of ED visits and readmissions $>30$ days after LRYGB. The secondary outcome measures are indications and risk factors for ED visits and readmissions.

\section{Study Selection}

Duplicate articles have been manually removed. Unique articles were screened by title and abstract by two independent reviewers (N.O. and S.M.), who also performed the full text screening, data extraction, and methodological quality assessment. Discrepancies were resolved by consensus or a third party (M.B.) if necessary.

Full texts of the selected articles were screened for eligibility. Inclusion criteria were as follows: (1) randomized controlled trials, prospective and retrospective cohort, and casecontrol studies; (2) articles with at least 50 patients included with a RYGB of which at least $80 \%$ laparoscopic and a maximum of $20 \%$ open surgeries; (3) data on ED visits and readmissions $>30$ days after LRYGB.

Exclusion criteria were as follows: (1) case reports, review articles, commentaries, letters to editors, abstracts only; (2) studies in other languages than English; (3) studies that report on revisional or robotic RYGB; (4) articles which only included children or adolescents.

The following data was extracted from the included articles using a predesigned extraction form: first author's family name, country, study design, time of operation, number of patients, demographic and clinical characteristics of patients (gender, age, preoperative BMI), duration of follow-up (FU), number of ED visits and/or readmissions, and indications and risk factors for ED visits and readmissions.

\section{Quality Assessment}

The methodological quality of the studies was assessed using the Newcastle-Ottawa scale (NOS) [21]. The NOS applies to observational studies only (cohort and case-control studies). This scale contains eight items belonging to three categories: (1) study group selection, (2) comparability of groups, and (3) outcome/exposure of interest. A study with a total score $>7$ was judged to be of high quality [21].

\section{Statistics}

Descriptive statistics are used. Data is presented in numbers and percentages, as mean or median with standard deviation (SD) or interquartile ranges, unless otherwise described. A meta-analysis could not be performed due to heterogeneity in the study characteristics and outcomes.

\section{Results}

\section{Study Selection}

The search strategy resulted in 9645 unique citations after excluding duplicates. Title and abstract were screened, and 356 articles were extracted of which the full texts were reviewed for eligibility. A total of twenty studies were included. Of these studies, six reported on ED visits [22-27] and 
nineteen on readmissions [23, 24, 26-42]. Figure 1 provides an overview of our literature search and study selection.

\section{Study and Patient Characteristics}

Study and patient characteristics and data on FU of all included studies are presented in Table 1. All included studies were retrospective cohort studies and case-control studies, published between 2008 and 2019. The FU for ED visits ranged between 60 days and 3 years and for readmissions between 6 weeks and 4.2 years after surgery.

Most studies were single-arm studies that reported outcomes only after LRYGB or two-armed studies involving different types of bariatric surgeries. Others were two-armed studies comparing results between Medicaid and nonMedicaid patients [23, 24], patients in which a different technique was used to close the gastrojejunostomy [30, 31, 36], or compared private practice versus an academic hospital [27].

The included studies comprised a total of 2818 patients with data about ED visits and 276,543 with data about readmissions. In all studies, the majority of patients were female (63.0-90.9\%), mean body mass index (BMI) ranged from $41.3-58.4 \mathrm{~kg} / \mathrm{m}^{2}$ and mean age from 38.2 to 48.7 years.

\section{Methodological Quality Assessment}

According to the NOS, only nine studies were of high quality [27, 28, 30-33, 36, 37, 39]. Most studies missed points due to the fact that they did not match patients or did not make any adjustment for confounders in the analysis. The outcome of the quality assessment is shown in Table 2.

\section{Emergency Department Visits}

An overview of the results on ED visits is presented in Table 3. Sixty days after surgery, the range for ED visits was $3.4-7.6 \%[26,27]$. The percentages of patients with an ED visit within 90 days after surgery ranged from 3.9 to $32.6 \%[23,24,26,28]$. Only one study by Cho et al. reported ED visits beyond 90 days. At 1 year, 2 years, and 3 years [25]
Fig. 1 Flow chart of the study selection

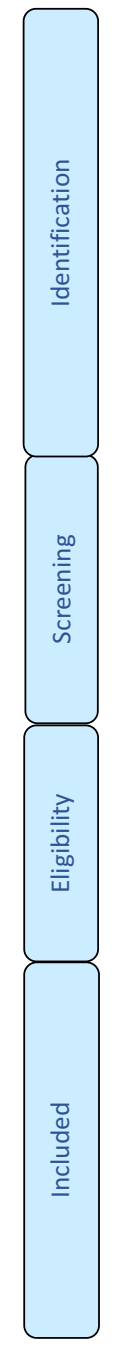

Records identified through database searching $(n=20738)$

- Pubmed 5585

- Embase 6483

- PsyciNFO 159

- Cochrane Library 975

- Scopus 7536
Additional records identified through other sources $(n=0)$

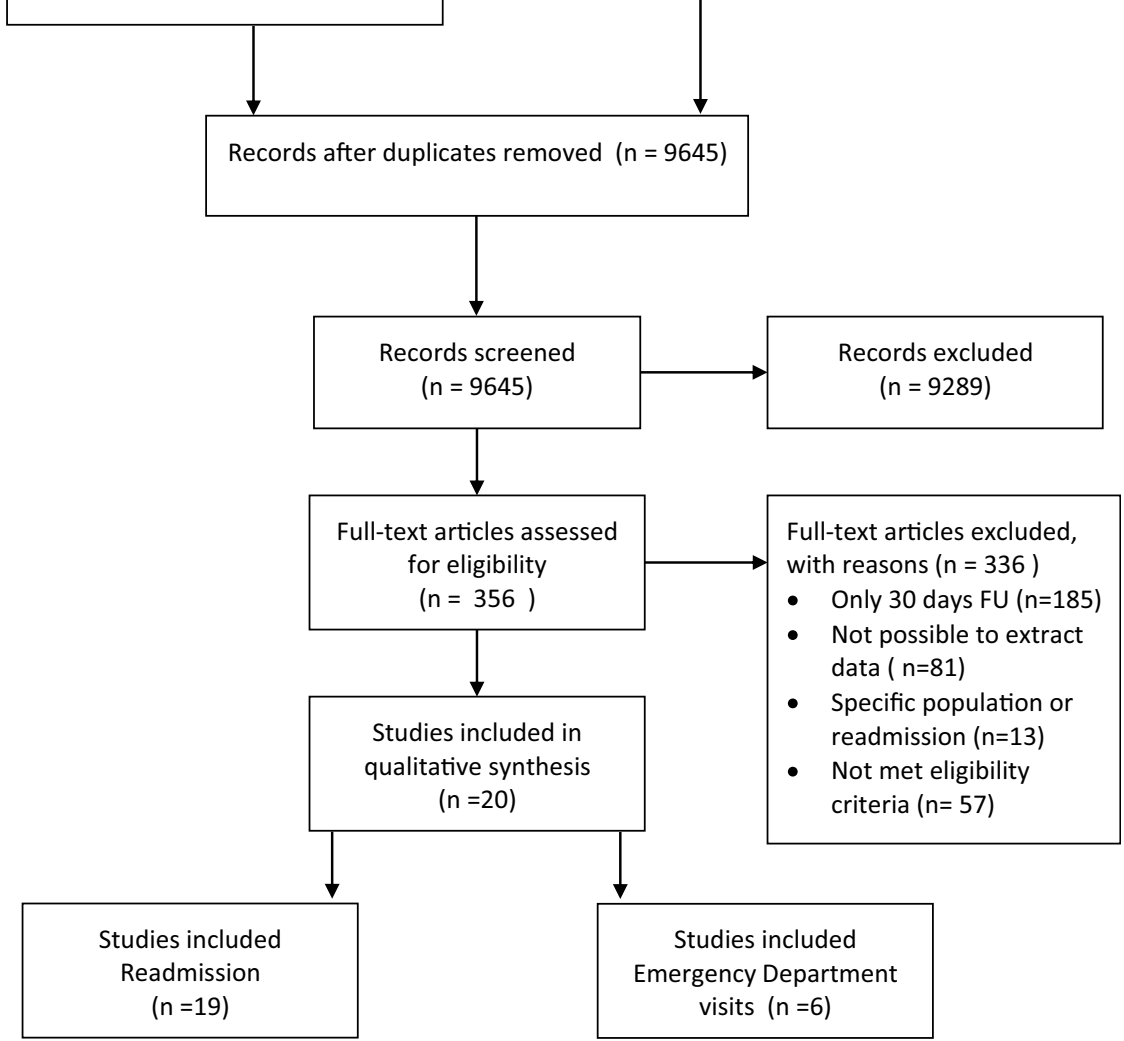




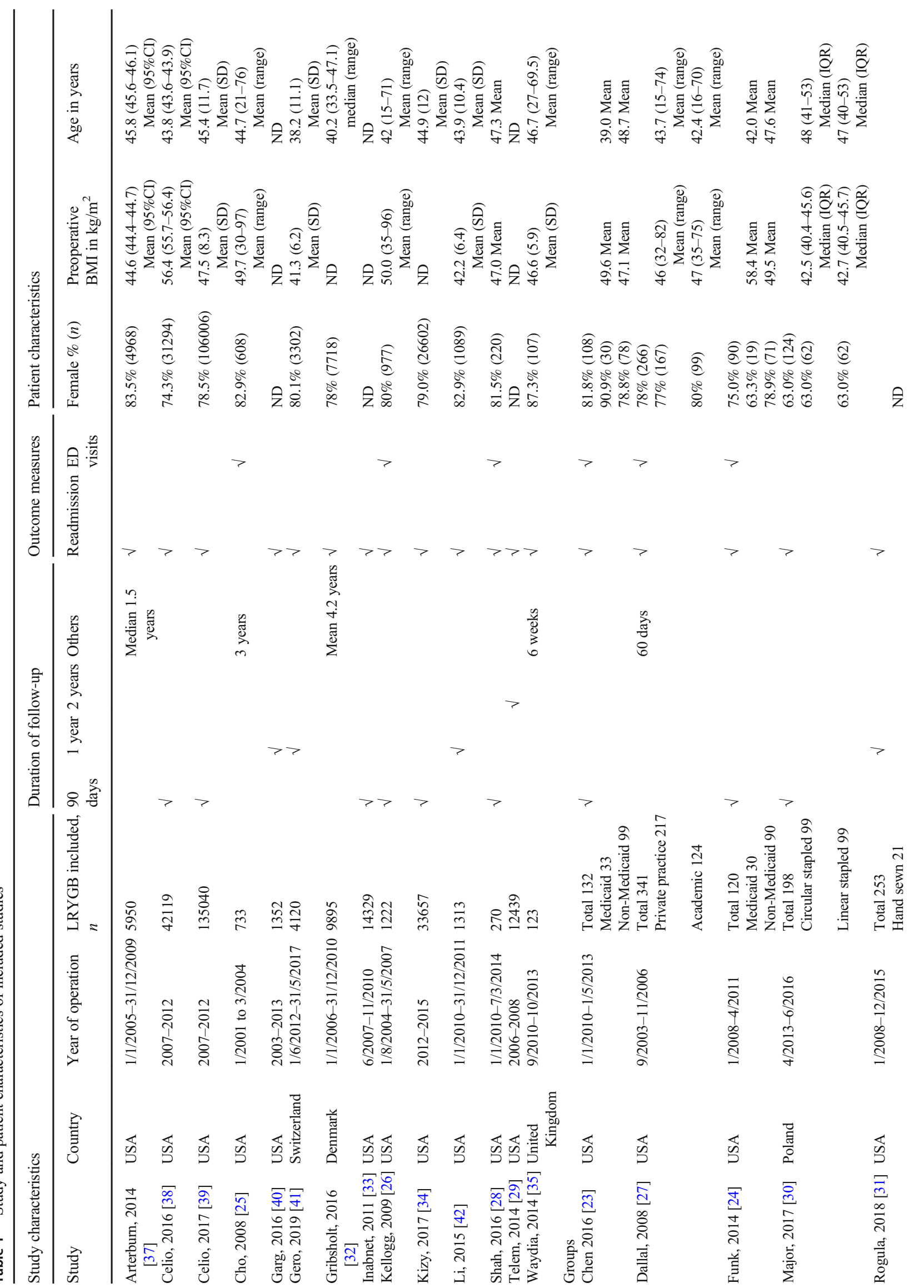


of $\mathrm{FU}$, rates of $\mathrm{ED}$ visits were $25.6 \%, 30 \%$, and $31.1 \%$ respectively.

The indications for ED visits are presented in Table 4. The main indications for ED visits at 90 days of FU were nausea and vomiting, dehydration, abdominal pain (cholelithiasis not included), and wound issues [26]. At 1,2, and 3 years of FU, main reasons were abdominal pain $(45.2 \%, 47.4 \%, 47.6 \%)$, nausea and vomiting $(18.4 \%, 17.9 \%, 18.4 \%)$, abdominal pain and vomiting combined $(16.7 \%, 15.6 \%, 15.1 \%)$, and other complaints $(19.7 \%, 19.2 \%, 19.0 \%)$ [25].

In addition, Cho et al. showed that $32.5 \%$ of all patients with an ED visit had more than 2 visits [25].

Funk et al. and Dallal et al. showed that Medicaid patients had significantly more ED visits than non-Medicaid patients $[24,27]$. Although not statistically significant $(p=0.06)$, the ED visits reported in the study by Chen et al. were nearly twice as common in Medicaid patients compared to nonMedicaid patients (48.2\% vs 27.4\%) [23]. Patients who underwent open surgery or patients who were unemployed, disabled, or retired were at higher risk for ED visits [26]. Furthermore, undergoing surgery at an academic hospital was associated with a higher risk of visiting the ED after LRYGB [27].

\section{Readmissions}

An overview of the results on readmissions is presented in Table 5. Within the first 90 days after surgery, the rates of readmission were between 4.1 and $20.5 \%$ [23, 24, 26, 28, $30,33,34,36,38-41]$. The number of patients readmitted within a 1-year FU ranged from 4.75 to $16.6 \%$ [31, 40-42]. One and a half year readmission was 19.9\% [37] and 2-year readmission was 29\% [29]. The study of Gribsholt et al. showed a readmission of $23.9 \%$ with a mean FU of 4.2 years [32].

The indications for readmissions and number of readmissions are presented in Table 6. Four studies showed indications for readmissions [26, 32, 40, 41]. The different timepoints of FU have shown similar reasons for readmissions in which abdominal pains, intestinal obstruction, gastrointestinal complaints including nausea and vomiting, and dietary complaints were most common.

The study by Telem et al. provides an overview on the number of readmissions per patient within a 2-year FU. Of all included patients, there was one readmission in $19 \%$ (2363), two to three readmissions in $8 \%$ (995), and four or more readmissions in 2\% (249) [29].

The same risk factors as for ED visits apply to readmissions: open surgery, unemployment, being disabled, retirement [26], Medicaid status, or undergoing surgery at an academic hospital [27]. 
Table 2 Methodological quality assessment using the NewcastleOttawa scale

\begin{tabular}{|c|c|c|c|c|}
\hline Study, year & Selection & Comparability & Outcome & Total \\
\hline Arterburn, 2014 [37] & $* * *$ & $* *$ & $* * *$ & $* * * * * * * *$ \\
\hline Celio, 2016 [38] & $* * *$ & $* *$ & $* *$ & $* * * * * *$ \\
\hline Celio, 2017 [39] & $* * *$ & . & $* * *$ & $* * * * * * *$ \\
\hline Cho, 2008 [25] & $* * *$ & . & $* *$ & $* * * * *$ \\
\hline Dallal, 2008 [27] & $* *$ & $* *$ & $* * *$ & $* * * * * * *$ \\
\hline Garg, 2016 [40] & $* * *$ & . & $* *$ & $* * * * *$ \\
\hline Gero, 2019 [41] & $* * *$ & . & $* * *$ & $* * * * * *$ \\
\hline Gribsholt, 2016 [32] & $* * *$ & $* *$ & $* * *$ & $* * * * * * * *$ \\
\hline Inabnet, 2011 [33] & $* * *$ & $* *$ & $* *$ & $* * * * * * *$ \\
\hline Kellogg, 2009 [26] & $* * *$ & . & $* *$ & $* * * * *$ \\
\hline Kizy, 2017 [34] & $* * *$ & . & $* *$ & $* * * * *$ \\
\hline $\mathrm{Li}, 2015$ [42] & $* * *$ & . & $* * *$ & $* * * * * *$ \\
\hline Rogula, 2018 [31] & $* * *$ & $* *$ & $* *$ & $* * * * * * *$ \\
\hline Roy, 2017 [36] & $* * *$ & $* *$ & $* *$ & $* * * * * * *$ \\
\hline Shah, 2016 [28] & $* * *$ & $* *$ & $* * *$ & $* * * * * * * *$ \\
\hline Telem, 2014 [29] & $* * *$ & . & $* *$ & $* * * * *$ \\
\hline Waydia, 2014 [35] & $* * *$ & . & $* *$ & $* * * * *$ \\
\hline Study, year & Selection & Comparability & Exposure & Total \\
\hline Chen 2016 [23] & $* *$ & . & $* * *$ & $* * * * *$ \\
\hline Funk, 2014 [24] & $* *$ & . & $* * *$ & $* * * * *$ \\
\hline Major, 2017 [30] & $* * *$ & $* *$ & $* *$ & $* * * * * * *$ \\
\hline
\end{tabular}

A study with a total score $>7^{*}$ was judged to be of high quality

\section{Discussion}

This systematic review is the first overview of long-term ED visits and readmissions after LRYGB. Available literature indicates that ED visits and readmissions after LRYGB are frequently seen. With regard to ED visits, one in three patients had at least one visit in the first 90 days after surgery [23, 24, $26,28]$. Remarkably, in our extensive search, we only found one study describing ED visits beyond 90 days. ED visits showed an increase over time with up to $31.1 \%$ of patients visiting the ED within 3 years after surgery [25]. The FU for the included studies with data on readmissions was up to 4.2

Table 3 Number of emergency department visits

\begin{tabular}{|c|c|c|c|c|c|c|}
\hline Study, year & Patients included, $n$ & $\begin{array}{l}\text { ED visits } 60 \\
\text { days } \%(n)\end{array}$ & $\begin{array}{l}\text { ED visits } 90 \\
\text { days } \%(n)\end{array}$ & $\begin{array}{l}\text { ED visits } 1 \\
\text { years } \%(n)\end{array}$ & $\begin{array}{l}\text { ED visits } 2 \\
\text { years } \%(n)\end{array}$ & $\begin{array}{l}\text { ED visits } 3 \\
\text { years } \%(n)\end{array}$ \\
\hline Cho, 2008 [25] & 733 & & & $25.6 \%(188)$ & $30 \%(220)$ & $31.1 \%(228)$ \\
\hline Kellogg, 2009 [26] & 1222 & $3.4 \%(41)$ & $3.9 \%(48)$ & & & \\
\hline Shah, 2016 [28] & 270 & & $27.1 \%(73)$ & & & \\
\hline \multicolumn{7}{|l|}{ Groups } \\
\hline \multirow[t]{3}{*}{ Chen 2016 [23] } & Total 132 & & $32.6 \%(43)$ & & & \\
\hline & Medicaid 33 & & $48.2 \%(16)$ & & & \\
\hline & Non-Medicaid 99 & & $27.4 \%(27)$ & & & \\
\hline \multirow[t]{3}{*}{ Dallal, 2008 [27] } & Total 341 & $7.6 \%(26)$ & & & & \\
\hline & Private practice 217 & $1.4 \%(3)$ & & & & \\
\hline & Academic 124 & $18.5 \%(23)$ & & & & \\
\hline \multirow[t]{3}{*}{ Funk, 2014 [24] } & Total 120 & & $15.8 \%(19)$ & & & \\
\hline & Medicaid 30 & & $33.3 \%(10)$ & & & \\
\hline & Non-Medicaid 90 & & $10.0 \%(9)$ & & & \\
\hline
\end{tabular}

ED visits emergency department visits 
Table 4 Indications for emergency department visits

\begin{tabular}{|c|c|c|c|c|}
\hline Study, year & $\begin{array}{l}\text { Indications for ED } \\
\text { visits in 90-day FU }\end{array}$ & $\begin{array}{l}\text { Indications for ED } \\
\text { visits in 1-year FU }\end{array}$ & $\begin{array}{l}\text { Indications for ED } \\
\text { visits in 2-year FU }\end{array}$ & $\begin{array}{l}\text { Indications for ED } \\
\text { visits in 3-year FU }\end{array}$ \\
\hline \multirow[t]{4}{*}{ Cho, 2008 [25] } & & Abdominal pain $45.2 \%$ & Abdominal pain $47.4 \%$ & Abdominal pain $47.6 \%$ \\
\hline & & Other complaints $19.7 \%$ & Other complaints $19.2 \%$ & Other complaints $19.0 \%$ \\
\hline & & Nausea and vomiting $18.4 \%$ & Nausea and vomiting $17.9 \%$ & Nausea and vomiting $18.4 \%$ \\
\hline & & $\begin{array}{l}\text { Abdominal pain and vomiting } \\
16.7 \%\end{array}$ & $\begin{array}{l}\text { Abdominal pain and vomiting } \\
15.6 \%\end{array}$ & $\begin{array}{l}\text { Abdominal pain and vomiting } \\
15.1 \%\end{array}$ \\
\hline \multirow{3}{*}{$\begin{array}{l}\text { Kellogg, } 2009 \\
\quad[26]\end{array}$} & Nausea/vomiting & & & \\
\hline & Dehydration & & & \\
\hline & $\begin{array}{l}\text { Abdominal pain } \\
\text { (without } \\
\text { cholelithiasis) } \\
\text { Wound issues }\end{array}$ & & & \\
\hline
\end{tabular}

$E D$ visits emergency visits, $F U$ follow-up

years post-surgery. Up to one in five patients was readmitted at least once within the first 90 days after surgery [23, 24, 26, $28,30,33,34,36,38-41]$. One-year readmission rate was up to $16.6 \%, 2$-year readmission rate was $29 \%$, and the percentage after 4.2 years of FU was $23.9 \%$ [29, 31, 32]. Five studies provided an overview of indications for ED visits and readmissions of which abdominal pain, intestinal obstruction, gastrointestinal complaints including nausea and vomiting, and dietary complaints were most common $[25,26,32,40$, 41]. Open surgery, unemployment, being disabled, retirement, Medicaid status, or undergoing surgery at an academic hospital were risk factors for ED visits and readmissions [23, 24, 26, 27]. But only little or no data on risk factors was found for both of our outcome measures. Only nine studies in the current literature had a FU beyond 90 days. In the context of the increase in bariatric surgery over the past three decades, it is striking to find this little evidence on long-term ED visits and readmissions.

Despite the sparse number of articles providing reasons for ED visits and readmissions, abdominal pain is a frequently reported indication $[25,26,32,41]$. Abdominal pain can be caused by some well-known reasons: internal herniation, ulcers at the gastrojejunal anastomosis, and cholelithiasis [14-18]. However, the burden of nonspecific complaints is considerable [25, 41]. The impact and extent of abdominal complaints is gaining more attention in the current literature [43]. In the article by Gormsen et al., 39\% of patients experienced abdominal pain in the past month, within a FU of 2-7 years after RYGB [44]. In a survey by Gribsholt et al., 54.4\% of patients experienced abdominal pain, $34.2 \%$ had abdominal pain leading to health care contact, and $18.5 \%$ had abdominal pain leading to hospitalization (symptoms of cholelithiasis and urolithiasis excluded) [19]. In the studies by Gormsen and Gribsholt, risk factors for abdominal pain were unemployment, retirement, women, patients younger than 35 , symptoms before LRYGB, postoperative complications, preoperative smoking, and preoperative use of strong analgesics $[19,44]$. Unemployment and retirement are consistent with the risk factors for ED visits and readmissions reported by Kellog et al. [26]. Hogestol et al. reported chronic abdominal pain in $33.8 \%$ of patients, indigestion in $48.8 \%$, and irritable bowel syndrome in $29.1 \%$. Mean FU was 64 months (SD 4.2) [45]. These data could confirm the fact that gastrointestinal complaints are another frequently mentioned cause for readmissions [40]. Future studies should elaborate on abdominal complaints in particular. Insight in ED visits and readmissions could provide more information on the impact, and the course of abdominal complaints through time after LRYGB.

It is common for one patient to have multiple ED visits or readmissions after LRYGB. The article by Cho et al. showed that, of all patients with an ED visit, 32.5\% had more than 2 visits [25]. In the study by Telem et al., $10 \%$ of all patients had 2 or more readmissions within 2 years of FU [29]. Furthermore, a wide variation was seen in the number of readmissions between patients. One patient had 22 readmissions [29]. Multiple visits could be the cause of a previously unresolved or chronic complaint. A lot of complaints could be present after LRYGB like diarrhea, fatigue, anemia, hypoglycemia, dumping, and cholelithiasis [19]. However, some complaints are more likely to occur on the short term after LRYGB due to adjustments a patient has to make after surgery, like dumping syndrome, and dehydration. Later on, diagnoses such as anemia and cholelithiasis are expected to appear more frequently.

The wide variation of the results in this review is remarkable, for example, the range from 4.1 to $20.5 \%$ for readmissions within 90 days of $\mathrm{FU}[23,41]$. These differences can be attributed to heterogeneity in the definitions used for ED visits and readmission in these studies. Some studies show 
Table 5 Number of readmissions

\begin{tabular}{|c|c|c|c|c|c|c|}
\hline Study, year & $\begin{array}{l}\text { Patients included, } \\
n\end{array}$ & $\begin{array}{l}\text { Readmission } 60 \\
\text { days } \%(n)\end{array}$ & $\begin{array}{l}\text { Readmission } 90 \\
\text { days } \%(n)\end{array}$ & $\begin{array}{l}\text { Readmission } 1 \\
\text { year \% }(n)\end{array}$ & $\begin{array}{l}\text { Readmission } 2 \\
\text { years } \%(n)\end{array}$ & $\begin{array}{l}\text { Time of FU: } \\
\text { readmission } \%(n)\end{array}$ \\
\hline Arterburn, 2014 [37] & 5800 & & & & & 1.5 years: $19.9 \%$ \\
\hline Celio, 2016 [38] & 38035 & & $9.2 \%$ (3499) & & & \\
\hline Celio, 2017 [39] & 135040 & & $6.6 \%(8913)$ & & & \\
\hline Garg, 2016 [40] & 1352 & & $6.14 \%(83)$ & $7.17 \%(97)$ & & 180 days: $6.2 \%(84)$ \\
\hline Gero, 2019 [41] & $\begin{array}{l}4120 \text { ( } 90 \text { days }) \\
3399 \text { ( } 1 \text { year })\end{array}$ & & $4.1 \%(169)$ & $9.4 \%(320)$ & & \\
\hline Gribsholt, 2016 [32] & 9895 & & & & & $\begin{array}{l}\text { Mean 4.2 IQR 3.5-5.3: } \\
\text { 23.9\% (2367) }\end{array}$ \\
\hline Inabnet, 2011 [33] & 14329 & & $7.6 \%(1094)$ & & & \\
\hline Kellogg, 2009 [26] & 1222 & $8.3 \%(102)$ & $10.3 \%(126)$ & & & \\
\hline Kizy, 2017 [34] & 33657 & & $7.8 \%(2625)$ & & & \\
\hline $\mathrm{Li}, 2015$ [42] & 1052 & & & $4.75 \%(50)$ & & \\
\hline Shah, 2016 [28] & 270 & & $12.3 \%(33)$ & & & \\
\hline Telem, 2014 [29] & 12439 & & & & $29 \%(3607)$ & \\
\hline Waydia, 2014 [35] & 123 & & & & & 6 weeks: $6.5 \%(8)$ \\
\hline \multicolumn{7}{|l|}{ Groups } \\
\hline \multirow[t]{2}{*}{ Chen 2016 [23] } & $\begin{array}{l}\text { Total } 132 \\
\text { Medicaid } 33\end{array}$ & & $\begin{array}{l}20.5 \%(27) \\
37 \%(12)\end{array}$ & & & \\
\hline & Non-Medicaid 99 & & $14.7 \%(15)$ & & & \\
\hline Dallal, 2008 [27] & $\begin{array}{l}\text { Total } 341 \\
\text { Private practice } \\
217 \\
\text { Academic } 124\end{array}$ & $\begin{array}{l}4.7 \%(16) \\
1.4 \%(3) \\
10.4 \%(13)\end{array}$ & & & & \\
\hline \multirow[t]{2}{*}{ Funk, 2014 [24] } & $\begin{array}{l}\text { Total } 120 \\
\text { Medicaid } 30\end{array}$ & & $\begin{array}{l}10 \%(12) \\
20 \%(6)\end{array}$ & & & \\
\hline & Non-Medicaid 90 & & $6.7 \%(6)$ & & & \\
\hline Major, 2017 [30] & $\begin{array}{l}\text { Total } 198 \\
\text { Circular stapled } \\
\quad 99 \\
\text { Linear stapled } 99\end{array}$ & & $\begin{array}{l}7.1 \%(14) \\
6.1 \%(6) \\
8.2 \%(8)\end{array}$ & & & \\
\hline \multirow[t]{3}{*}{ Rogula, 2018 [31] } & $\begin{array}{l}\text { Total } 253 \\
\text { Hand sewn } 21\end{array}$ & & & $\begin{array}{l}16.6 \%(42) \\
14 \%(3)\end{array}$ & & \\
\hline & $\begin{array}{l}\text { Circular stapled } \\
82\end{array}$ & & & $28 \%(23)$ & & \\
\hline & $\begin{array}{l}\text { Linear stapled } \\
150\end{array}$ & & & $11 \%(16)$ & & \\
\hline \multirow[t]{2}{*}{ Roy, 2017 [36] } & $\begin{array}{l}\text { Total } 13670 \\
\text { Powered stapler } \\
\quad 4057\end{array}$ & $\begin{array}{l}\text { Total } 7.2 \%(978) \\
6.8 \%(274)\end{array}$ & $\begin{array}{l}\text { Total } 7.9 \%(1076) \\
7.6 \%(308)\end{array}$ & & & \\
\hline & $\begin{array}{l}\text { Manual stapler } \\
9613\end{array}$ & $7.3 \%(704)$ & $8.0 \%(768)$ & & & \\
\hline
\end{tabular}

$I Q R$ interquartile range

all causes for ED visits and readmissions [29, 37, 46, 47] whereas Kellog et al. and Gribsholt et al. only report surgery-related data [26, 32]. Other studies do not specify whether they are related to surgery or not. This could explain, for instance, why Telem et al. reported a higher rate of readmissions at 2 years FU, than Gribsholt et al. at 4.2 years of FU [29, 32]. This makes it difficult to draw conclusions from the results.
Due to the heterogeneity in reported data, pooling of data and meta-analysis was not possible. Underlying causes of these variations are the retrospective design of all studies; wide variation in confounding factors in case of baseline criteria like gender, age, and BMI; variation in the definitions used for ED visits and readmission; and great diversity in times of FU. An important limitation of our study is that we could only include retrospective 
Table 6 Additional information about readmissions

\begin{tabular}{|c|c|c|c|}
\hline \multicolumn{4}{|c|}{ Indications for readmission } \\
\hline Study, year & $\begin{array}{l}\text { Indications for readmission } \\
\text { in 90-day FU }\end{array}$ & $\begin{array}{l}\text { Indications for readmission } \\
\text { in 1-year FU \% ( } n)\end{array}$ & $\begin{array}{l}\text { Indications for readmission } \\
\text { in } 4.2 \text { years }(3.5-5.3) \text { mean (IQR) FU }\end{array}$ \\
\hline \multirow[t]{7}{*}{ Garg, $2016[40]$} & & $\begin{array}{l}\text { GI:**36.1\% (35) } \\
\text { Dietary:*29.9\% (29) }\end{array}$ & \\
\hline & & VTE: $9.28 \%(9)$ & \\
\hline & & Bleed: $8.25 \%(8)$ & \\
\hline & & Pulmonary: $5.15 \%$ (5) & \\
\hline & & SSI/wound/abscess: $5.15 \%$ & \\
\hline & & Anastomotic leak: $4.12 \%$ (4) & \\
\hline & & Other: $2.06 \%(2)$ & \\
\hline \multirow[t]{3}{*}{ Gero, 2019 [41] } & $\begin{array}{l}\text { Abdominal pain of unknown } \\
\text { origin }\end{array}$ & Abdominal pain of unknown origin & \\
\hline & Dysphagia & Symptomatic cholecytolithiasis & \\
\hline & Internal herniation/bowel obstruction & Internal herniation/bowel obstruction & \\
\hline \multirow[t]{2}{*}{ Gribsholt, 2016 [32] } & & & Abdominal pain $62.8 \%$ \\
\hline & & & Intestinal obstruction $21.7 \%$ \\
\hline \multirow[t]{3}{*}{ Kellogg, 2009 [26] } & $\begin{array}{l}\text { Nausea/vomiting } \\
\text { Dehydration }\end{array}$ & & \\
\hline & $\begin{array}{l}\text { Abdominal pain } \\
\quad \text { (without cholelithiasis) }\end{array}$ & & \\
\hline & Wound issues & & \\
\hline \multicolumn{4}{|c|}{ Number of readmissions } \\
\hline \multirow{4}{*}{$\begin{array}{l}\text { Study, year } \\
\text { Telem, } 2014 \text { [29] }\end{array}$} & Number of readmissions & Readmission 2 year \% (n) & \\
\hline & 1 & $19 \%(2363)$ & \\
\hline & 2 or 3 & $8 \%(995)$ & \\
\hline & 4 or more & $2 \%(249)$ & \\
\hline
\end{tabular}

*Vitamin deficiency, dehydration, elektrolyte imbalance

**Ulcers, strictures, and bowel obstruction

GI gastro-intestinal, VTE venous thromboembolism, SSI surgical site infection

studies. The evidence is subject to the disadvantages of retrospective data and selection bias. Another limitation is the coding for the types and approaches of bariatric surgeries over time. Since separate codes for laparoscopic procedures did not yet exist, it is not inconceivable that coding in the early stages of procedures included the open approach. This could have caused publication of biased results in these studies. The third limitation was already mentioned in the "Methodological Quality Assessment" section, as most of the studies lack information about confounding. Finally, the biggest confounder in this systematic review is the variation in the definitions used for ED visits and readmission.

\section{Conclusion}

The number of ED visits and readmissions shows the severity of the long-term problems faced by bariatric patients and caregivers after LRYGB. While abundant evidence shows limited ED visits and readmissions in the first 30 days, this review shows ED visits and readmissions in nearly one in three patients long term after LRYGB. We can conclude that the majority of all ED visits and readmissions will take place longer than 30 days after surgery. This demonstrates that ED visits and readmissions, in the first 30 days after surgery, do not adequately reproduce the magnitude of postoperative problems faced by patients after LRYGB. Therefore, long-term FU after LRYGB should extend well beyond the first 30 postoperative days

More long-term prospective data after LRYGB is needed. Understanding the long-term problems after bariatric surgery is crucial for optimizing the choice for a specific procedure and long-term post-bariatric care.

Abdominal pain is the main reason for ED visits and readmissions after LRYGB. Insight into ED visits and readmissions could provide more information about the 
impact and course of abdominal complaints over time after LRYGB.

Supplementary Information The online version contains supplementary material available at https://doi.org/10.1007/s11695-021-05286-0.

\section{Declarations}

Conflict of Interest The authors declare no competing interests.

Open Access This article is licensed under a Creative Commons Attribution 4.0 International License, which permits use, sharing, adaptation, distribution and reproduction in any medium or format, as long as you give appropriate credit to the original author(s) and the source, provide a link to the Creative Commons licence, and indicate if changes were made. The images or other third party material in this article are included in the article's Creative Commons licence, unless indicated otherwise in a credit line to the material. If material is not included in the article's Creative Commons licence and your intended use is not permitted by statutory regulation or exceeds the permitted use, you will need to obtain permission directly from the copyright holder. To view a copy of this licence, visit http://creativecommons.org/licenses/by/4.0/.

\section{References}

1. Ng M, Fleming T, Robinson M, et al. Global, regional, and national prevalence of overweight and obesity in children and adults during 1980-2013: a systematic analysis for the Global Burden of Disease Study 2013. Lancet. 2014;384:766-81. https://doi.org/10.1016/ S0140-6736(14)60460-8.

2. Chooi YC, Ding C, Magkos F. The epidemiology of obesity. Metabolism. 2019;92:6-10. https://doi.org/10.1016/j.metabol. 2018.09.005.

3. Devito NJ, French L, Goldacre B. Trends in obesity and severe obesity prevalence in US youth and adults by sex and age, 2007-2008 to 2015-2016 Downloaded From: by a University Of North Carolina Chapel Hill User on 08/21/2018. Jama. 2018;319:2016-8.

4. Angrisani L, Santonicola A, Iovino P, et al. IFSO Worldwide Survey 2016: primary, endoluminal, and revisional procedures. Obes Surg. 2018;28:3783-94. https://doi.org/10.1007/s11695018-3450-2.

5. Welbourn R, Hollyman M, Kinsman R, et al. Bariatric surgery worldwide: baseline demographic description and one-year outcomes from the Fourth IFSO Global Registry Report 2018. Obes Surg. 2019;29: 782-95. https://doi.org/10.1007/s11695-018-3593-1.

6. Buchwald HA, Braunwald Y, Jensen E, et al. Bariatric surgery a systematic review and meta analysis. JAMA. 2004;292:1724-8.

7. Schauer PR, Bhatt DL, Kirwan JP, et al. Bariatric surgery versus intensive medical therapy for diabetes - 5-year outcomes. N Engl J Med. 2017;376:641-51. https://doi.org/10.1056/NEJMoa1600869.

8. Adams TD, Davidson LE, Litwin SE, et al. Health benefits of gastric bypass surgery after 6 years. Jama. 2012;308:1122-31. https:// doi.org/10.1001/2012.jama.11164.

9. Obeid NR, Malick W, Concors SJ, et al. Long-term outcomes after Roux-en-Y gastric bypass: 10- to 13-year data. Surg Obes Relat Dis. 2016;12:11-20. https://doi.org/10.1016/j.soard.2015.04.011.

10. Peter C, Fong MD, David S, et al. Effects of bariatric surgery on mortality in Swedish obese subjects. N Engl J Med. 2009;361:12334. https://doi.org/10.1056/NEJMoa0900212.

11. Sippey M, Kasten KR, Chapman WHH, et al. 30-day readmissions after sleeve gastrectomy versus Roux-en-Y gastric bypass. Surg
Obes Relat Dis. 2016;12:991-6. https://doi.org/10.1016/j.soard. 2016.01.036.

12. Telem DA, Yang J, Altieri M, Patterson W, Peoples B, Chen H, et al. Rates and risk factors for unplanned emergency department utilization and hospital readmission following bariatric surgery. Ann Surg 2016;263:956-60. 10.1097/SLA.0000000000001536.

13. Howell MH, Praiss A, Podolsky D, et al. A single-center experience examining the length of stay and safety of early discharge after laparoscopic Roux-en-Y gastric bypass surgery. Obes Surg. 2018;28:1225-31. https://doi.org/10.1007/s11695-017-2993-y.

14. Wanjura V, Sandblom G, Österberg J, et al. Cholecystectomy after gastric bypass - incidence and complications. Surg Obes Relat Dis. 2017;13:979-87. https://doi.org/10.1016/j.soard.2016.12.004.

15. Coupaye M, Castel B, Sami O, et al. Comparison of the incidence of cholelithiasis after sleeve gastrectomy and Roux-en-Y gastric bypass in obese patients: a prospective study. Surg Obes Relat Dis. 2015;11:779-84. https://doi.org/10.1016/j.soard.2014.10.015.

16. Altieri MS, Yang J, Nie L, et al. Incidence of cholecystectomy after bariatric surgery. Surg Obes Relat Dis. 2018;14:992-6. https://doi. org/10.1016/j.soard.2018.03.028.

17. Aghajani E, Nergaard BJ, Leifson BG, et al. The mesenteric defects in laparoscopic Roux-en-Y gastric bypass: 5 years follow-up of non-closure versus closure using the stapler technique. Surg Endosc. 2017;31:3743-8. https://doi.org/10.1007/s00464-0175415-2.

18. Coblijn UK, Goucham AB, Lagarde SM, et al. Development of ulcer disease after Roux-en-Y gastric bypass, incidence, risk factors, and patient presentation: a systematic review. Obes Surg. 2014;24:299-309. https://doi.org/10.1007/s11695-013-1118-5.

19. Gribsholt SB, Pedersen AM, Svensson E, et al. Prevalence of selfreported symptoms after gastric bypass surgery for obesity. JAMA Surg. 2016;151:504-11. https://doi.org/10.1001/jamasurg.2015. 5110.

20. Moher D, Liberati A, Tetzlaff J, Altman DG, Altman D, Antes G, et al. Preferred reporting items for systematic reviews and metaanalyses: the PRISMA statement. PLoS Med. 2009;6. https://doi. org/10.1371/journal.pmed.1000097.

21. G. Wells, B. Shea. The Newcastle-Ottawa Scale (NOS) for assessing the quality of nonrandomised studies in meta-analyses. n.d.

22. Shah AS, Campos GM. Single-incision laparoscopic sleeve gastrectomy: Is it worth it? Surg Obes Relat Dis. 2016;12:935-6. https:// doi.org/10.1016/j.soard.2016.01.012.

23. Chen EY, Fox BT, Suzo A, et al. One-year surgical outcomes and costs for Medicaid versus non-Medicaid patients undergoing laparoscopic Roux-en-Y gastric bypass: a single-center study. Surg Laparosc Endosc Percutaneous Tech. 2016;26:38-43. https://doi. org/10.1097/SLE.0000000000000219.

24. Funk LM, Suzo A, Mikami DJ, et al. Two-year outcomes for Medicaid patients undergoing laparoscopic Roux-en-Y gastric bypass: a case-control study. Obes Surg. 2014;24:1679-85. https:// doi.org/10.1007/s11695-014-1236-8.

25. Cho M, Kaidar-Person O, Szomstein S, et al. Emergency room visits after laparoscopic Roux-en-Y gastric bypass for morbid obesity. Surg Obes Relat Dis. 2008;4:104-9. https://doi.org/10.1016/j. soard.2007.05.008.

26. Kellogg TA, Swan T, Leslie DA, et al. Patterns of readmission and reoperation within 90 days after Roux-en-Y gastric bypass. Surg Obes Relat Dis. 2009;5:416-23. https://doi.org/10.1016/j.soard. 2009.01.008.

27. Dallal RM, Bailey L, Guenther L, et al. Comparative analysis of short-term outcomes after bariatric surgery between two disparate populations. Surg Obes Relat Dis. 2008;4:110-4. https://doi.org/10. 1016/j.soard.2007.04.007. 
28. Shah N, Greenberg JA, Leverson G, et al. Weight loss after bariatric surgery: a propensity score analysis. J Surg Res. 2016;202:449-54. https://doi.org/10.1016/j.jss.2016.01.041.

29. Telem DA, Talamini M, Gesten F, et al. Hospital admissions greater than 30 days following bariatric surgery: patient and procedure matter. Surg Endosc Other Interv Tech. 2015;29:1310-5. https:// doi.org/10.1007/s00464-014-3834-x.

30. Major P, Janik MR, Wysocki M, et al. Comparison of circular-and linear-stapled gastrojejunostomy in laparoscopic Roux-en-Y gastric bypass: a multicenter study. Wideochirurgia I Inne Tech Maloinwazyjne. 2017;12:140-6. https://doi.org/10.5114/wiitm. 2017.66868 .

31. Rogula T, Koprivanac M, Janik MR, et al. Does robotic Roux-en-Y gastric bypass provide outcome advantages over standard laparoscopic approaches? Obes Surg. 2018;28:2589-96. https://doi.org/ 10.1007/s11695-018-3228-6.

32. Gribsholt SB, Svensson E, Richelsen B, et al. Rate of acute hospital admissions before and after Roux-en-Y gastric bypass surgery. Ann Surg. $2016 ;$ XX:1. https://doi.org/10.1097/SLA. 0000000000002113

33. Inabnet WB, Winegar DA, Sherif B, et al. Early outcomes of bariatric surgery in patients with metabolic syndrome: an analysis of the bariatric outcomes longitudinal database. J Am Coll Surg. 2012;214:550-6. https://doi.org/10.1016/j.jamcollsurg.2011.12. 019.

34. Kizy S, Jahansouz C, Downey MC, et al. National trends in bariatric surgery 2012-2015: demographics, procedure selection, readmissions, and cost. Obes Surg. 2017;27:2933-9. https:/doi. org/10.1007/s11695-017-2719-1.

35. Waydia S, Gunawardene A, Gilbert J, et al. 23-Hour/next day discharge post-laparoscopic Roux-en-Y gastric bypass (LRYGB) surgery is safe. Obes Surg. 2014;24:2007-10. https://doi.org/10.1007/ s11695-014-1409-5.

36. Roy S, Yoo A, Yadalam S, et al. Comparison of economic and clinical outcomes between patients undergoing laparoscopic bariatric surgery with powered versus manual endoscopic surgical staplers. J Med Econ. 2017;20:423-33. https://doi.org/10.1080/ 13696998.2017.1296453.

37. Arterburn D, Powers JD, Toh S, et al. Comparative effectiveness of laparoscopic adjustable gastric banding vs laparoscopic gastric bypass. JAMA Surg. 2014;149:1279-87. https://doi.org/10.1001/ jamasurg.2014.1674.
38. Celio AC, Wu Q, Kasten KR, et al. Comparative effectiveness of Roux-en-Y gastric bypass and sleeve gastrectomy in super obese patients. Surg Endosc Other Interv Tech. 2016;31:317-23. https:// doi.org/10.1007/s00464-016-4974-y.

39. Celio AC, Kasten KR, Schwoerer A, et al. Perioperative safety of laparoscopic versus robotic gastric bypass: a propensity matched analysis of early experience. Surg Obes Relat Dis. 2017;13:184752. https://doi.org/10.1016/j.soard.2017.07.016.

40. Garg T, Rosas U, Rogan D, et al. Characterizing readmissions after bariatric surgery. J Gastrointest Surg. 2016;20:1797-801. https:// doi.org/10.1007/s11605-016-3247-3.

41. Gero D, Raptis DA, Vleeschouwers W, et al. Defining global benchmarks in bariatric surgery: a retrospective multicenter analysis of minimally invasive Roux-en-Y gastric bypass and sleeve gastrectomy. Ann Surg. 2019;270:859-67. https://doi.org/10. 1097/SLA.0000000000003512.

42. Li RA, Fisher DP, Dutta S, et al. Bariatric surgery results: reporting clinical characteristics and adverse outcomes from an integrated healthcare delivery system. Surg Obes Relat Dis. 2015;11:111925. https://doi.org/10.1016/j.soard.2015.03.002.

43. Mala T, Høgestøl I. Abdominal pain after Roux-En-Y gastric bypass for morbid obesity. Scand J Surg. 2018;107:277-84. https:// doi.org/10.1177/1457496918772360.

44. Gormsen J, Burcharth J, Gögenur I, et al. Prevalence and risk factors for chronic abdominal pain after Roux-en-Y gastric bypass surgery. Ann Surg. 2019;XX:1. https://doi.org/10.1097/sla. 0000000000003356.

45. Hogestol IK, Chahal-Kummen M, Eribe I, et al. Chronic abdominal pain and symptoms 5 years after gastric bypass for morbid obesity. Obes Surg. 2016; https://doi.org/10.1007/s11695-016-2499-z.

46. Kelles SMB, Barreto SM, Guerra HL. Costs and usage of healthcare services before and after open bariatric surgery. Sao Paulo Med J. 2011;129:291-9.

47. Zingmond DS, McGory ML, Ko CY. Hospitalization before and after gastric bypass surgery. J Am Med Assoc. 2005;294:1918-24. https://doi.org/10.1001/jama.294.15.1918.

Publisher's Note Springer Nature remains neutral with regard to jurisdictional claims in published maps and institutional affiliations. 